The Federal Reserve BanK of Kansas City Research Working Papers

Monetary Policy, Trend Inflation, and the Great Moderation: An Alternative Interpretation: Comment Based on System Estimation

Yasuo Hirose, Takushi Kurozumi and Willem Van Zandweghe $=$ actage December 2015 RWP 15-17 


\title{
Monetary Policy, Trend Inflation, and the Great Moderation: An Alternative Interpretation: Comment Based on System Estimation*
}

\author{
Yasuo Hirose $^{\dagger} \quad$ Takushi Kurozumi ${ }^{\ddagger} \quad$ Willem Van Zandweghe ${ }^{\S}$
}

December 2015

\begin{abstract}
What caused the U.S. economy's shift from the Great Inflation era to the Great Moderation era? A large literature shows that the shift was achieved by the change in monetary policy from a passive to an active response to inflation. However, Coibion and Gorodnichenko (2011) attribute the shift to a fall in trend inflation along with the policy change, based on a solely estimated Taylor rule and a calibrated staggered-price model. We estimate the Taylor rule and the staggered-price model jointly and demonstrate that the change in monetary policy responses to inflation and other variables suffices for explaining the shift.

JEL Classification: C11; E31; E52

Keywords: Equilibrium indeterminacy; Great Inflation; Great Moderation; Monetary policy; Trend inflation

${ }^{*}$ The authors are grateful for comments and discussions to Olivier Coibion, Taeyoung Doh, Yuriy Gorodnichenko, Alejandro Justiniano, Mototsugu Shintani, and Alexander Wolman, as well as seminar participants at the Federal Reserve Bank of Kansas City. The views expressed in this paper are those of the authors and do not necessarily reflect the official views of the Bank of Japan, the Federal Reserve Bank of Kansas City or the Federal Reserve System.

${ }^{\dagger}$ Keio University. E-mail address: yhirose@econ.keio.ac.jp

${ }^{\ddagger}$ Bank of Japan. E-mail address: takushi.kurozumi@boj.or.jp

${ }^{\S}$ Federal Reserve Bank of Kansas City. E-mail address: willem.vanzandweghe@kc.frb.org
\end{abstract}




\section{Introduction}

What caused the shift from the Great Inflation era to the Great Moderation era in the U.S. economy? Since the seminal work by Clarida, Galí, and Gertler (2000), a large body of literature has regarded the Great Inflation era as a consequence of indeterminate equilibrium, which lasted until determinacy was restored in the Great Moderation era. ${ }^{1}$ This literature has established the view that the U.S. economy's shift from indeterminacy to determinacy was achieved by the change in the Fed's policy from a passive to an active response to inflation. Clarida, Galí, and Gertler demonstrate this view by estimating a monetary policy rule of the sort proposed by Taylor (1993) and combining it with a calibrated sticky-price model to analyze determinacy. Lubik and Schorfheide (2004) reach the same conclusion as Clarida, Galí, and Gertler using a distinct method. They estimate a Taylor rule and a sticky-price model jointly using a Bayesian likelihood approach that allows for indeterminacy. ${ }^{2}$

The recent paper of Coibion and Gorodnichenko (2011) challenges this view by arguing that the U.S. economy's shift from indeterminacy in the Great Inflation era to determinacy in the Great Moderation era was largely caused by a fall in trend inflation along with the increase in the Fed's policy response to inflation. According to recent studies, such as Ascari and Ropele (2009), Hornstein and Wolman (2005), and Kiley (2007), higher trend inflation makes equilibrium more susceptible to indeterminacy in staggered-price models where each period a fraction of prices is kept unchanged on the basis of micro evidence on price adjustment. ${ }^{3}$ Particularly, to guarantee determinacy in such models, higher trend

\footnotetext{
${ }^{1}$ Our paper follows Coibion and Gorodnichenko (2011) to focus on the explanation of the Great Inflation era from the perspective of monetary policy. Other explanations emphasize relatively high volatility of shocks to the U.S. economy (e.g., Sims and Zha, 2006; Justiniano and Primiceri, 2008) or the absence of inventory management that emerged in the Great Moderation era (e.g., Kahn, McConnell, and Perez-Quirós, 2002).

${ }^{2}$ Moreover, Boivin and Giannoni (2006) indicate, using a counterfactual experiment, that in order to explain the U.S. economy's shift from the Great Inflation era to the Great Moderation era, it is crucial for the Fed's policy to have changed the way it has, along with a change in shocks to the economy.

${ }^{3}$ See also Kobayashi and Muto (2013), Kurozumi (2014, 2016), and Kurozumi and Van Zandweghe (2016a, b). Ascari and Sbordone (2014) review this strand of literature. For recent micro evidence on price adjustment, see, e.g., Kehoe and Midrigan (2015), Klenow and Kryvtsov (2008), Klenow and Malin (2010), and Nakamura and Steinsson $(2008,2013)$.
} 
inflation calls for a stronger monetary policy response to inflation, and for moderate-to-high trend inflation, such a policy response must be more aggressive than that suggested by the Taylor principle, which claims that the nominal interest rate should be raised by more than the increase in inflation. In light of this finding, Coibion and Gorodnichenko estimate a Taylor rule - where the federal funds rate responds to its past rates, expected inflation, the output gap, and output growth - during a period before 1979 and a period after 1982, and then combine it with a calibrated staggered-price model with trend inflation to conduct a counterfactual experiment on the Taylor rule's responses and trend inflation for the two periods. According to their experiment, the U.S. economy was likely in the indeterminacy region of the parameter space before 1979, whereas after 1982 the economy was likely in the determinacy region, in line with the results of Clarida, Galí, and Gertler (2000) and Lubik and Schorfheide (2004). However, Coibion and Gorodnichenko argue that the change in the Taylor rule's responses from their pre-1979 estimates to the post-1982 ones alone is not sufficient to rule out indeterminacy, unless trend inflation falls from their calibrated level for the pre-1979 period to that for the post-1982 period.

This paper re-examines the role of trend inflation in the U.S. economy's shift from indeterminacy in the Great Inflation era to determinacy in the Great Moderation era. Specifically, our paper employs the method of Lubik and Schorfheide (2004) to jointly estimate the Taylor rule and the staggered-price model with trend inflation during a period before 1979 and a period after 1982, allowing for indeterminacy. ${ }^{4}$ Our approach with full-information likelihood-based estimation of the whole model complements the limited-information estimation of the Taylor rule by Coibion and Gorodnichenko (2011), as the approach of Lubik and Schorfheide (2004) complements that of Clarida, Galí, and Gertler (2000). The full-information likelihood-based estimation optimally adjusts estimates of the Taylor rule's responses for the endogeneity of its targeted variables. Moreover, because cross-equation restrictions that link the Taylor rule and decision rules of other agents in the model are exploited, it is possible to simultaneously identify other model parameters that characterize

\footnotetext{
${ }^{4}$ The Bayesian likelihood approach developed by Lubik and Schorfheide (2004) has been used in recent studies, such as Benati and Surico (2009), Bhattarai, Lee, and Park (2012, 2015) and Hirose (2007, 2008, 2013).
} 
equilibrium determinacy, including the level of trend inflation. ${ }^{5}$

Our estimation results show that the change in the Taylor rule's responses to all the targeted variables from the pre-1979 to the post-1982 estimates alone suffices for explaining the U.S. economy's shift from indeterminacy to determinacy, regardless of the estimated decline in trend inflation. That is, the switch of the policy responses not only to inflation but also to the other targeted variables - in particular, the output gap and output growth — played an essential role in the shift. This finding extends the literature's view on the U.S. economy's shift from the Great Inflation era to the Great Moderation era by emphasizing the importance of the change in monetary policy responses to the targeted variables other than inflation. As Coibion and Gorodnichenko (2011) point out, a decrease in the policy response to the output gap and an increase in the policy response to output growth, as well as a rise in the policy response to inflation, all made determinacy more likely in the Great Moderation era.

Our finding contrasts starkly with the argument of Coibion and Gorodnichenko (2011). Among several differences between their paper and ours, what is crucial lies in the treatment of the level of trend inflation in the pre-1979 and post-1982 periods. Our full-information estimation of the whole model can identify the trend inflation level, whereas their limitedinformation estimation of the Taylor rule cannot, and thus they calibrate it. ${ }^{6}$ Our estimates of trend inflation in the two periods are in line with those of Cogley and Sbordone (2008), while the calibrated values of Coibion and Gorodnichenko (2011) are higher than our estimates. Such higher calibrated values greatly increase the effect of the decline in trend inflation on the shift from indeterminacy to determinacy, since higher trend inflation makes equilibrium more susceptible to indeterminacy in the model. ${ }^{7}$

\footnotetext{
${ }^{5}$ For the approach of Clarida, Galí, and Gertler (2000) that conducts a limited-information estimation of a Taylor rule, Mavroeidis (2010) points to limitations of their approach and emphasizes the need to make use of identifying assumptions that can be derived from the full structure of their model.

${ }^{6}$ Coibion and Gorodnichenko (2011) estimate a constant term of the Taylor rule, which contains not only trend inflation but also other factors. Consequently, the level of trend inflation is not identifiable.

${ }^{7}$ An independent work by Arias et al. (2015) extends the analysis of Coibion and Gorodnichenko (2011) using the medium-scale model of Christiano, Eichenbaum, and Evans (2005). Specifically, their work estimates the model without price or wage indexation for the long sample period 1960:I-2008:II and combines it with the Taylor rule estimated by Coibion and Gorodnichenko to conduct the same counterfactual experiment as in Coibion and Gorodnichenko. Consequently, they confirm the conclusion of Coibion and Gorodnichenko
} 
The remainder of the paper proceeds as follows. Section 2 presents a staggered-price model with trend inflation and a Taylor rule as in Coibion and Gorodnichenko (2011). Section 3 explains our strategy and data for estimating the whole model jointly. Section 4 shows results of our empirical analysis. Section 5 concludes.

\section{The Model}

The model consists of a Taylor rule and a (discrete-time) staggered-price model of Calvo (1983) that features a non-zero rate of trend inflation. This is the same as the model of Coibion and Gorodnichenko (2011) except for two modifications made for estimation. First, our model incorporates a third shock, to preferences, in addition to the shocks to productivity growth and the Taylor rule that are present in their model, because our estimation uses three data series (inflation, output growth, and the nominal interest rate). Second, our model introduces (external) habit formation in consumption preferences to generate output persistence, since the Bayesian likelihood approach of Lubik and Schorfheide (2004) may have a bias toward indeterminacy if the model in question lacks sufficient persistence, as discussed between Beyer and Farmer (2007) and Lubik and Schorfheide (2007).

This section presents the log-linearized model for estimation. Details of the model are described in Appendix.

\subsection{The log-linearized model for estimation}

The log-linearized equilibrium conditions are given by

$\hat{y}_{t}=\frac{h}{a+h}\left(\hat{y}_{t-1}-z_{a, t}\right)+\frac{a}{a+h}\left(E_{t} \hat{y}_{t+1}+E_{t} z_{a, t+1}\right)-\frac{a-h}{a+h}\left(\hat{r}_{t}-E_{t} \hat{\pi}_{t+1}\right)+\frac{a-h}{a+h}\left(z_{u, t}-E_{t} z_{u, t+1}\right)$,

that the fall in trend inflation from the level calibrated for the Great Inflation era to that for the Great Moderation era played a crucial role in the U.S. economy's shift from indeterminacy to determinacy, which is in sharp contrast with our finding. 


$$
\begin{aligned}
\hat{\pi}_{t}= & \beta E_{t} \hat{\pi}_{t+1}+\frac{1-\lambda \pi^{\theta-1}}{\lambda \pi^{\theta-1}(1+\theta / \eta)}\left[\left(1-\beta \lambda \pi^{\theta+\frac{\theta}{\eta}}\right)\left(1+\frac{1}{\eta}\right) \hat{y}_{t}+\frac{h\left(1-\beta \lambda \pi^{\theta-1}\right)}{a-h}\left(\hat{y}_{t}-\hat{y}_{t-1}+z_{a, t}\right)\right] \\
& -\frac{\beta\left(\pi^{1+\frac{\theta}{\eta}}-1\right)\left(1-\lambda \pi^{\theta-1}\right)}{1+\theta / \eta} z_{u, t}+\psi_{t} \\
\psi_{t}= & \beta \lambda \pi^{\theta+\frac{\theta}{\eta}} E_{t} \psi_{t+1}+\frac{\beta\left(\pi^{1+\frac{\theta}{\eta}}-1\right)\left(1-\lambda \pi^{\theta-1}\right)}{1+\theta / \eta} \\
& \times\left\{\left(\theta+\frac{\theta}{\eta}\right) E_{t} \hat{\pi}_{t+1}+\left(1-\beta \lambda \pi^{\theta+\frac{\theta}{\eta}}\right)\left[\left(1+\frac{1}{\eta}\right) E_{t} \hat{y}_{t+1}+E_{t} z_{u, t+1}\right]\right\} \\
\hat{r}_{t}= & \phi_{r 1} \hat{r}_{t-1}+\phi_{r 2} \hat{r}_{t-2}+\left(1-\phi_{r 1}-\phi_{r 2}\right)\left[\phi_{\pi} E_{t} \hat{\pi}_{t+1}+\phi_{x} \hat{x}_{t}+\phi_{\Delta y}\left(\hat{y}_{t}-\hat{y}_{t-1}+z_{a, t}\right)\right]+z_{r, t} \\
\hat{x}_{t}= & \hat{y}_{t}-\hat{y}_{t}^{n} \\
\hat{y}_{t}^{n}= & \frac{h \eta}{a(1+\eta)-h}\left(\hat{y}_{t-1}^{n}-z_{a, t}\right)
\end{aligned}
$$

where hatted variables denote log-deviations from steady-state or trend levels.

Eq. (1) is a spending Euler equation, where $\hat{y}_{t}$ is (detrended) output, $\hat{r}_{t}$ is the monetary policy rate, $\hat{\pi}_{t}$ is inflation, $z_{u, t}$ is a preference shock, $z_{a, t}$ is a (non-stationary) technology shock, $E_{t}$ is the rational-expectations operator conditional on information available in period $t, h \in[0,1]$ represents the degree of habit persistence in consumption preferences, and $a$ is the steady-state gross rate of technological change, which equals the steady-state gross rate of balanced growth. Eq. (2) is a generalized New Keynesian Phillips curve, where $\psi_{t}$ is an (endogenous) auxiliary variable, $\beta \in(0,1)$ is the subjective discount factor, $\lambda \in[0,1)$ is the probability of no price adjustment, $\pi$ is the gross rate of steady-state or trend inflation, $\theta>1$ is the price elasticity of demand, and $\eta \geq 0$ is the elasticity of labor supply. Eq. (3) describes the dynamics of the auxiliary variable $\psi_{t}$. Note that Eq. (2) indeed generalizes the New Keynesian Phillips curve because it can be reduced to

$$
\hat{\pi}_{t}=\beta E_{t} \hat{\pi}_{t+1}+\frac{(1-\lambda)(1-\beta \lambda)(1+1 / \eta)}{\lambda(1+\theta / \eta)} \hat{y}_{t}
$$

when the trend inflation rate is zero (i.e., $\pi=1$ ), which implies $\psi_{t}=0$ in Eq. (3), and there is no habit persistence (i.e., $h=0$ ). Eq. (4) is a Taylor rule that adjusts the policy rate $\hat{r}_{t}$ in response to the past rates $\hat{r}_{t-1}, \hat{r}_{t-2}$, the expected inflation rate $E_{t} \hat{\pi}_{t+1}$, the output gap $\hat{x}_{t}$, and the output growth rate $\hat{y}_{t}-\hat{y}_{t-1}+z_{a, t}$, where $\phi_{r 1}, \phi_{r 2}, \phi_{\pi}, \phi_{x}, \phi_{\Delta y}$ are the degrees of monetary policy responses to these targeted variables and $z_{r, t}$ is a monetary policy shock. 
Eq. (5) is the definition of the output gap $\hat{x}_{t}$, while $\hat{y}_{t}^{n}$ denotes the natural rate of output (the output that could be obtained if prices were flexible, that is, $\lambda=0$ ) and its law of motion is given by Eq. (6). Note that a steady-state condition determines the subjective discount factor as $\beta=\pi a / r$, where $r$ is the steady-state gross policy rate.

Each of the three shocks $z_{i, t}, i \in\{u, a, r\}$ is assumed to follow the stationary first-order autoregressive process

$$
z_{i, t}=\rho_{i} z_{i, t-1}+\varepsilon_{i, t}
$$

where $\rho_{i} \in[0,1)$ is the autoregressive parameter and $\varepsilon_{i, t} \sim$ i.i.d. $N\left(0, \sigma_{i}^{2}\right)$ is the innovation to each shock.

\section{The Econometric Strategy and Data}

This section describes our strategy and data for estimating the log-linearized model presented in the preceding section. Previous studies, such as Ascari and Ropele (2009), Coibion and Gorodnichenko (2011), Kurozumi (2014), and Kurozumi and Van Zandweghe (2016a), show that higher trend inflation makes equilibrium more susceptible to indeterminacy in Calvo staggered-price models where each period a fraction of prices is kept unchanged. Our paper thus follows Lubik and Schorfheide (2004) to construct a likelihood function of the model for the indeterminacy region of the parameter space as well as the determinacy region. ${ }^{8}$

This section first explains our method for solving linear rational-expectations (LRE) models under equilibrium indeterminacy and then presents our Bayesian method for estimating the model presented above, in addition to data used in estimation.

\footnotetext{
${ }^{8}$ The estimation strategy of Lubik and Schorfheide (2004) allows for indeterminacy of equilibrium by including a sunspot shock and its related arbitrary coefficient matrix in solutions to linear rational-expectations models. By estimating the arbitrary matrix with a fairly loose prior on it, a set of particular solutions that are most consistent with data can be selected from a full set of solutions.
} 


\subsection{Rational-expectations solutions under indeterminacy}

Lubik and Schorfheide (2003) show a full set of solutions to LRE models by extending the solution algorithm developed by Sims (2002). ${ }^{9}$ Any LRE model can be written in the canonical form

$$
\Gamma_{0}(\vartheta) s_{t}=\Gamma_{1}(\vartheta) s_{t-1}+\Psi(\vartheta) \varepsilon_{t}+\Pi(\vartheta) \xi_{t},
$$

where $\Gamma_{0}(\vartheta), \Gamma_{1}(\vartheta), \Psi(\vartheta)$, and $\Pi(\vartheta)$ are conformable matrices of coefficients that depend on structural parameters $\vartheta, s_{t}$ is a vector of endogenous variables including those expected at time $t, \varepsilon_{t}$ is a vector of fundamental shocks, and $\xi_{t}$ is a vector of forecast errors. Specifically, in our model, these vectors are given by

$$
\begin{aligned}
& s_{t}=\left[\hat{y}_{t}, \hat{\pi}_{t}, \hat{\psi}_{t}, \hat{r}_{t}, \hat{r}_{t-1}, \hat{y}_{t}^{n}, \hat{x}_{t}, z_{u, t}, z_{a, t}, z_{r, t}, E_{t} \hat{y}_{t+1}, E_{t} \hat{\pi}_{t+1}, E_{t} \hat{\psi}_{t+1}\right]^{\prime}, \\
& \varepsilon_{t}=\left[\varepsilon_{u, t}, \varepsilon_{a, t}, \varepsilon_{r, t}\right]^{\prime} \\
& \xi_{t}=\left[\left(\hat{y}_{t}-E_{t-1} \hat{y}_{t}\right),\left(\hat{\pi}_{t}-E_{t-1} \hat{\pi}_{t}\right),\left(\hat{\psi}_{t}-E_{t-1} \hat{\psi}_{t}\right)\right]^{\prime}
\end{aligned}
$$

According to Lubik and Schorfheide (2003), a full set of solutions to the LRE model (8) is of the form

$$
s_{t}=\Phi_{x}(\vartheta) s_{t-1}+\Phi_{\varepsilon}(\vartheta, \tilde{M}) \varepsilon_{t}+\Phi_{\zeta}(\vartheta) \zeta_{t},
$$

where $\Phi_{x}(\vartheta), \Phi_{\varepsilon}(\vartheta, \tilde{M})$, and $\Phi_{\zeta}(\vartheta)$ are coefficient matrices, $\tilde{M}$ is an arbitrary matrix, and $\zeta_{t}$ is a reduced-form sunspot shock, which is a non-fundamental disturbance. ${ }^{10}$ For estimation, it is assumed that $\zeta_{t} \sim$ i.i.d. $N\left(0, \sigma_{\zeta}^{2}\right)$. When equilibrium is determinate, the solution (9) is reduced to

$$
s_{t}=\Phi_{x}^{D}(\vartheta) s_{t-1}+\Phi_{\varepsilon}^{D}(\vartheta) \varepsilon_{t}
$$

The solution (9) possesses two important features under indeterminacy. First, the equilibrium dynamics is driven not only by the fundamental shocks $\varepsilon_{t}$ but also by the sunspot

\footnotetext{
${ }^{9}$ Sims (2002) generalizes the solution algorithm of Blanchard and Kahn (1980) and characterizes one particular solution - which is called the "orthogonality solution" - in case of equilibrium indeterminacy. In this solution, the contribution of fundamental shocks and sunspot shocks to forecast errors is orthogonal.

${ }^{10}$ Lubik and Schorfheide (2003) originally express the last term in (9) as $\Phi_{\zeta}\left(\theta, M_{\zeta}\right) \zeta_{t}$, where $M_{\zeta}$ is an arbitrary matrix and $\zeta_{t}$ is a vector of sunspot shocks. For identification, Lubik and Schorfheide (2004) impose the normalization $M_{\zeta}=1$ with the dimension of the sunspot shock vector being unity. Such a normalized shock is referred to as a "reduced-form sunspot shock" in that it contains beliefs associated with all the expectational variables.
} 
shock $\zeta_{t}$. Second, the equilibrium representation cannot be unique due to the presence of the arbitrary matrix $\tilde{M}$, that is, the model induces indeterminate solutions. Therefore, to specify the law of motion of the endogenous variables $s_{t}$, the matrix $\tilde{M}$ must be pinned down.

This paper infers the matrix $\tilde{M}$ from the data, following Lubik and Schorfheide (2004). In their approach, $\tilde{M}$ is replaced with $M^{*}(\vartheta)+M$, where $M^{*}(\vartheta)$ is selected so that equilibrium responses of the endogenous variables $s_{t}$ to the fundamental shocks $\varepsilon_{t}$ are continuous at the boundary between determinacy and indeterminacy regions of the parameter space, and where $M$ is estimated with prior mean zero. ${ }^{11}$ While Lubik and Schorfheide (2004) analytically calculate the matrix $M^{*}(\vartheta)$ for a prototypical sticky-price model, the present paper numerically computes it for our model.

\subsection{Bayesian inference}

The model is estimated using Bayesian methods for both determinacy and indeterminacy regions of the parameter space. Following Lubik and Schorfheide (2004), the likelihood function for a sample of observations $X^{T}=\left[X_{1}, \ldots, X_{T}\right]^{\prime}$ is given by

$$
\mathcal{L}\left(\vartheta, M \mid X^{T}\right)=\left\{\vartheta \in \Theta^{D}\right\} \mathcal{L}^{D}\left(\vartheta \mid X^{T}\right)+\left\{\vartheta \in \Theta^{I}\right\} \mathcal{L}^{I}\left(\vartheta, M \mid X^{T}\right)
$$

where $\Theta^{D}, \Theta^{I}$ are determinacy and indeterminacy regions of the parameter space, $f(\vartheta)=$ $\left\{\vartheta \in \Theta^{i}\right\}$ is the indicator function that equals one if $\vartheta \in \Theta^{i}$ and zero otherwise, and $\mathcal{L}^{D}\left(\vartheta \mid X^{T}\right), \mathcal{L}^{I}\left(\vartheta, M \mid X^{T}\right)$ are likelihood functions of the state-space models that consist of observation equations and the determinacy solution (10) or the indeterminacy solution (9). Then, by Bayes' theorem it follows that updating a prior distribution $p(\vartheta, M)$ with the sample $X^{T}$ gives rise to the posterior distribution

$$
p\left(\vartheta, M \mid X^{T}\right)=\frac{\mathcal{L}\left(\vartheta, M \mid X^{T}\right) p(\vartheta, M)}{p\left(X^{T}\right)}=\frac{\mathcal{L}\left(\vartheta, M \mid X^{T}\right) p(\vartheta, M)}{\int \mathcal{L}\left(\vartheta, M \mid X^{T}\right) p(\vartheta, M) d \vartheta \cdot d M} .
$$

Markov Chain Monte Carlo methods are then used to generate draws from this posterior distribution. ${ }^{12}$ Based on these draws, inferences about parameters of the model are made.

\footnotetext{
${ }^{11}$ The solution associated with the matrix $M^{*}(\vartheta)$ is referred to as the "continuity solution."

${ }^{12}$ In the estimation, 200,000 draws are generated using a random-walk Metropolis-Hastings algorithm, and the first 20,000 draws are discarded.
} 


\subsection{The data}

Three U.S. quarterly time series are used for estimation. The set of observables contains the output growth rate $100 \Delta \log Y_{t}$, the inflation rate $100 \log \pi_{t}$, and the nominal interest rate $100 \log r_{t}$. These data are respectively the per-capita real GDP growth rate, the inflation rate of the GDP implicit price deflator, and the federal funds rate. Moreover, like Coibion and Gorodnichenko (2011), who follow Orphanides (2004) to conduct their estimation using realtime data in the Federal Reserve Board's Greenbook forecast, our paper takes into account the fact that monetary policymakers make decisions based on contemporaneously available information. Therefore, our estimation uses the contemporaneously realized rates of output growth and inflation in the Real-Time Data Set for Macroeconomists provided by the Federal Reserve Bank of Philadelphia. ${ }^{13}$

Observation equations that relate the data to model variables are given by

$$
\left[\begin{array}{c}
100 \Delta \log Y_{t} \\
100 \log \pi_{t} \\
100 \log r_{t}
\end{array}\right]=\left[\begin{array}{c}
\bar{a} \\
\bar{\pi} \\
\bar{r}
\end{array}\right]+\left[\begin{array}{c}
\hat{y}_{t}-\hat{y}_{t-1}+z_{a, t} \\
\hat{\pi}_{t} \\
\hat{r}_{t}
\end{array}\right],
$$

where $\bar{a}=100(a-1), \bar{\pi}=100(\pi-1)$, and $\bar{r}=100(a \pi / \beta-1)$ are the steady-state rates of output growth, inflation, and nominal interest.

To examine the sources of the shift from the Great Inflation era to the Great Moderation era, the model is estimated for two sample periods: the pre-1979 sample from 1965:IV to 1979:II and the post-1982 sample from 1982:IV to 2007:III. The first sample period starts in 1965:IV because the real-time data is available only from 1965:IV. As in Coibion and Gorodnichenko (2011), the Volcker-disinflation period 1979:III-1982:III is excluded from the sample. The second sample ends in 2007:III, as our estimation strategy is not able to deal with the zero lower bound constraint on nominal interest rates.

\subsection{Prior distributions}

Although the elasticity of labor supply is fixed at $\eta=1$ to avoid an identification issue, all of the other parameters are estimated. The prior distributions of parameters to be estimated

\footnotetext{
${ }^{13}$ We have confirmed that our main results do not change qualitatively even when we use revised data instead of the real-time data.
} 
are shown in Table 1. For the spending habit persistence $h$ and the probability of no price adjustment $\lambda$, the priors are set to be beta distributions with mean of 0.5 . The prior of the price elasticity of demand $\theta$ is chosen to be a gamma distribution with mean of 10 , which is the same as the value calibrated by Coibion and Gorodnichenko (2011). For the monetary policy responses to inflation and the output gap $\phi_{\pi}, \phi_{x}$, our paper follows Smets and Wouters (2007) to set each prior mean at 1.50 and $0.125(=0.5 / 4)$ respectively, while it allows for twice larger standard deviations of 0.5 and 0.1 than theirs. The prior mean of the monetary policy response to output growth $\phi_{\Delta y}$ is set at 0.75 , based on the estimate of Coibion and Gorodnichenko. For the policy rate smoothing parameters $\phi_{r 1}, \phi_{r 2}$, our paper assigns normal distributions with mean of 1 and 0 , respectively, and standard deviation of 0.2 , as in Arias et al. (2015). The priors of the steady-state rates of output growth, inflation, and nominal interest $\bar{a}, \bar{\pi}, \bar{r}$ are distributed around their averages over the sample from 1965:IV to 2007:III. Regarding the structural shocks, the prior distributions of the autoregressive parameters $\rho_{i}, i \in\{u, a, r\}$ are beta distributions with mean of 0.7 and standard deviation of 0.2 , while those of the standard deviations of the shock innovations $\sigma_{i}, i \in\{u, a, r\}$ are inverse gamma distributions with mean of 0.5 and standard deviation of infinity. For the indeterminacy-solution coefficients $M_{i}, i \in\{u, a, r\}$, our paper assigns relatively loose priors; specifically, normal distributions with mean zero and standard deviation of unity. The prior of the standard deviation of the sunspot shock $\sigma_{\zeta}$ is an inverse gamma distribution with mean of 0.5 and standard deviation of infinity.

According to these prior distributions, the prior probability of determinacy of equilibrium in the model is almost even, i.e., 0.493, which suggests that there is a priori no substantial bias toward determinacy or indeterminacy.

\section{Results of Empirical Analysis}

This section presents the results of the empirical analysis. First, the estimation results are explained. Then, the main question of what caused the shift from indeterminacy of equilibrium in the Great Inflation era to determinacy in the Great Moderation era is addressed. 


\subsection{Estimation results}

Before interpreting the estimation results, it should be stressed that the U.S. economy was likely in the indeterminacy region of the parameter space before 1979, whereas after 1982 the economy was likely in the determinacy region, in line with the existing literature, such as Clarida, Galí, and Gertler (2000), Lubik and Schorfheide (2004), and Coibion and Gorodnichenko (2011). By analyzing the posterior distribution's probability mass assigned to the determinacy and indeterminacy regions, our paper finds that the posterior probability of determinacy is zero in the pre-1979 period, whereas it is unity in the post-1982 period.

Each parameter's posterior mean and 90 percent credible interval for the pre-1979 and post-1982 periods are reported in Table 2. As stressed by Coibion and Gorodnichenko (2011), this table shows that trend inflation fell to a marked extent. The posterior-mean estimate of the annualized trend inflation rate $4 \bar{\pi}$ declined from $4.75(=4 \times 1.19)$ percent to $2.95(=4 \times 0.74)$ percent. $^{14}$ This decline is comparable to that in the time-varying trend inflation rate estimated by Cogley and Sbordone (2008), who show that it fell from roughly 4.75 percent in the 1970 s to around 1.65 percent at the end of their sample (2003:IV).

Regarding the monetary policy responses, there are two substantial changes in the estimates from the pre-1979 to the post-1982 period that are significant in that the 90 percent credible intervals do not overlap between the two sample periods. First, the monetary policy response to inflation rose substantially, as indicated in the literature. The posterior-mean estimate increased from $\phi_{\pi}=1.31$ to $\phi_{\pi}=2.70$. This increase is comparable to that estimated by Coibion and Gorodnichenko, who show that the estimate of the policy response to inflation rose from 1.04 to 2.20 (in their mixed Taylor rule). One point to be stressed here is that the pre-1979 estimate of $\phi_{\pi}=1.31$ satisfies the Taylor principle (i.e., $\phi_{\pi}>1$ ) but induces indeterminacy in the staggered-price model with trend inflation, depending on the estimates of the other parameters. ${ }^{15}$ Second, the monetary policy response to the out-

\footnotetext{
${ }^{14}$ Coibion and Gorodnichenko (2011) estimate a constant term of the Taylor rule, which contains not only trend inflation but also other factors. Consequently, trend inflation is not identifiable in their estimation, and thus they calibrate the annualized rate of trend inflation at 6 percent for the pre-1979 period and at 3 percent for the post-1982 period.

${ }^{15}$ Orphanides (2004) estimates a Taylor rule using real-time data in the Federal Reserve Board's Greenbook forecast and obtains the estimate of the monetary policy response to a one-period ahead inflation forecast of
} 
put gap diminished considerably. The posterior-mean estimate decreased from $\phi_{x}=0.43$ to $\phi_{x}=0.11$. Such a decrease is in line with the findings of Orphanides (2004) and Coibion and Gorodnichenko. The estimate of the policy response to the output gap by Orphanides fell from $0.12(=0.46 / 4)$ to $0.05(=0.18 / 4)$, and that by Coibion and Gorodnichenko declined from $0.13(=0.52 / 4)$ to $0.11(=0.43 / 4)$. Moreover, the monetary policy response to output growth increased (its posterior-mean estimate rose from $\phi_{\Delta y}=0.73$ to $\phi_{\Delta y}=0.77$ ), whereas the sum of the policy responses to the past policy rates changed little.

As for the other structural parameters (i.e., $h, \theta, \lambda, \bar{a}, \bar{r})$, their 90 percent credible intervals overlap between the pre-1979 and post-1982 periods, indicating that these parameters do not change significantly between the two periods. ${ }^{16}$

The next subsection thus focuses on the changes in the monetary policy responses and trend inflation to investigate sources of the shift from indeterminacy of equilibrium in the pre-1979 period to determinacy in the post-1982 period.

\subsection{Sources of the shift from the Great Inflation era to the Great Moderation era}

This subsection addresses the main question of what caused the shift from indeterminacy of equilibrium in the Great Inflation era to determinacy in the Great Moderation era in the U.S. economy. Particularly, in light of the estimation results presented in the preceding section, our paper examines sources of the shift by focusing on the changes in the monetary policy responses and trend inflation.

Figure 1 uses the posterior-mean estimates of the model parameters to illustrate how the

1.49, which satisfies the Taylor principle. Consequently, he claims that self-fulfilling expectations could not have been the source of instability in the Great Inflation era. This claim, however, does not necessarily hold for the staggered-price model employed in the present paper, because the Taylor principle is not a sufficient condition for equilibrium determinacy when trend inflation is relatively high, as also stressed by Coibion and Gorodnichenko (2011).

${ }^{16}$ Although the posterior-mean estimate of the probability of no price adjustment decreased, its 90 percent credible interval is relatively wide in both the pre-1979 and post-1982 periods and overlaps between these two periods, and thus we can consider that this parameter does not change significantly between the two periods. This view is generally consistent with the literature reviewed by Nakamura and Steinsson (2013). 
determinacy region of the parameter space for the annualized trend inflation rate $4 \bar{\pi}$ and the monetary policy response to inflation $\phi_{\pi}$ expands with changes in the other parameter estimates. In each panel of the figure, the mark " $\times$ ", "*", and "o" respectively represent the pair of $\left(4 \bar{\pi}^{\text {pre } 79}, \phi_{\pi}^{\text {pre } 79}\right),\left(4 \bar{\pi}^{\text {pre } 79}, \phi_{\pi}^{\text {post } 82}\right)$, and $\left(4 \bar{\pi}^{\text {post } 82}, \phi_{\pi}^{\text {post } 82}\right)$, where $\bar{\pi}^{\text {pre } 79}, \phi_{\pi}^{\text {pre } 79}, \bar{\pi}^{\text {post } 82}$, and $\phi_{\pi}^{\text {post } 82}$ denote the posterior-mean estimates of the trend inflation rate and the policy response to inflation in the pre-1979 and post-1982 periods.

Panel (a) shows the case in which values of all the model parameters (of course, except trend inflation and the policy response to inflation) are fixed at the pre-1979 estimates. In this panel, the pair of the pre-1979 estimates of trend inflation and the policy response to inflation $\left(4 \bar{\pi}^{\text {pre } 79}, \phi_{\pi}^{\text {pre } 79}\right)$ - which is represented by " $\times$ " — lies in the indeterminacy region of the parameter space.

Panel (b) illustrates the case in which the values of the monetary policy responses to all the targeted variables change from the pre-1979 to the post-1982 estimates, keeping the other model parameters fixed at the pre-1979 estimates. In this panel, the pair of the pre-1979 estimates of trend inflation and the policy response to inflation $\left(4 \bar{\pi}^{\text {pre }}{ }^{79}, \phi_{\pi}^{\text {pre }}{ }^{2}\right)$ are still in the indeterminacy region, whereas the pair of the pre-1979 estimate of trend inflation and the post-1982 estimate of the policy response to inflation $\left(4 \bar{\pi}^{\text {pre }} 79, \phi_{\pi}^{\text {post } 82}\right)$ — which is denoted by "*" - is within the determinacy region. Therefore, the change in the policy responses to all the targeted variables suffices for explaining the U.S. economy's shift from indeterminacy to determinacy, without the decline in trend inflation.

One point to be emphasized here is that the difference between panels (a) and (b) is caused by the change in values of the monetary policy responses to the output gap and output growth from the pre-1979 to the post-1982 estimates. Indeed, almost the same panel as (b) can be obtained in the case where values of the policy responses to the two targeted variables change from the pre-1979 to the post-1982 estimates, keeping the other model parameters (including the policy responses to the past policy rates) fixed at the pre1979 estimates. Hence, the change in the policy responses to inflation, the output gap, and output growth is sufficient to attain the shift. This conclusion contrasts starkly with that of Coibion and Gorodnichenko (2011), who argue that the switch of monetary policy responses from their pre-1979 estimates to the post-1982 ones alone is not sufficient to rule out indeterminacy, unless trend inflation declines from their calibrated level for the pre- 
1979 period (i.e., 6 percent at an annualized rate) to that for the post-1982 period (i.e., 3 percent). One crucial source of the sharp contrast between their and our conclusions is that their calibrated values of trend inflation in the two periods are higher than our estimates. Such higher calibrated values greatly increase the effect of the decline in trend inflation on the shift from indeterminacy to determinacy, since higher trend inflation makes equilibrium more susceptible to indeterminacy in the model. Indeed, in panel (b), if the annualized trend inflation rate is 6 percent as Coibion and Gorodnichenko calibrate for the pre-1979 period, then the switch of the monetary policy responses to all the targeted variables from the pre-1979 to the post-1982 estimates alone is not sufficient to achieve determinacy.

Panel (c) presents the case in which the values of all the model parameters change from the pre-1979 to the post-1982 estimates. In this panel, the pair of the post-1982 estimates

of trend inflation and the policy response to inflation $\left(4 \bar{\pi}^{\text {post } 82}, \phi_{\pi}^{\text {post } 82}\right)$ - which is represented by "o" - stays inside the determinacy region. The difference between panels (b) and (c) suggests that small changes in the estimates of structural parameters - although they may not be significant in terms of the credible intervals - have a combined effect that further made determinacy more likely in the Great Moderation era.

These panels demonstrate that, for the U.S. economy's shift from indeterminacy in the Great Inflation era to determinacy in the Great Moderation era, the estimated change in the monetary policy responses to all the targeted variables - in particular, inflation, the output gap, and output growth - is sufficient and that the estimated decline in trend inflation is not necessary. This finding extends the literature's view on the U.S. economy's shift by emphasizing the importance of the change in monetary policy responses to the targeted variables other than inflation.

\section{Conclusion}

This paper has revisited the question of what caused the U.S. economy's shift from indeterminacy of equilibrium in the Great Inflation era to determinacy in the Great Moderation era. While a large body of literature, including Clarida, Galí, and Gertler (2000) and Lubik and Schorfheide (2004), has established the view that the U.S. economy's shift was achieved by the change in the Fed's policy from a passive to an active response to inflation, Coibion 
and Gorodnichenko (2011) attribute the shift to a fall in trend inflation along with the Fed's policy change, based on a solely estimated Taylor rule and a calibrated staggered-price model with trend inflation. The present paper has used the method of Lubik and Schorfheide (2004) to estimate the Taylor rule and the staggered-price model with trend inflation jointly during the Great Inflation and Moderation eras. Our results of the full-information estimation of the whole model have demonstrated that the change in monetary policy responses to inflation and other variables - in particular, the output gap and output growth - from the pre-1979 to the post-1982 estimates alone suffices for explaining the U.S. economy's shift from indeterminacy to determinacy, regardless of the estimated decline in trend inflation. 


\section{Appendix}

\section{A Details of the Model}

In the model economy, there are a representative household, a representative final-good firm, a continuum of intermediate-good firms, and a central bank. This appendix describes each agent's behavior in turn.

\section{A.1 The household}

The representative household consumes final goods $\tilde{C}_{t}$, supplies labor $\left\{l_{t}(i)\right\}$ specific to each intermediate-good firm $i \in[0,1]$, and purchases one-period riskless bonds $B_{t}$ so as to maximize the utility function

$$
E_{0} \sum_{t=0}^{\infty} \beta^{t} \exp \left(z_{u, t}\right)\left(\log \left(\tilde{C}_{t}-h C_{t-1}\right)-\frac{\int_{0}^{1}\left(l_{t}(i)\right)^{1+1 / \eta} d i}{1+1 / \eta}\right)
$$

subject to the budget constraint

$$
P_{t} \tilde{C}_{t}+B_{t}=\int_{0}^{1} P_{t} W_{t}(i) l_{t}(i) d i+r_{t-1} B_{t-1}+T_{t}
$$

where $E_{t}$ is the rational-expectations operator conditional on information available in period $t, \beta \in(0,1)$ is the subjective discount factor, $h \in[0,1]$ represents the degree of (external) habit persistence in consumption preferences, $\eta \geq 0$ is the elasticity of labor supply, $P_{t}$ is the price of final goods, $W_{t}(i)$ is the real wage paid by intermediate-good firm $i, r_{t}$ is the gross nominal interest rate on bonds, which is assumed to equal the monetary policy rate, $T_{t}$ consists of lump-sum public transfers and firm profits, and $z_{u, t}$ is a shock to the discount factor.

In the presence of complete insurance markets, the first-order conditions for utility maximization with respect to consumption, labor supply, and bond holdings become

$$
\begin{aligned}
\Xi_{t} & =\frac{\exp \left(z_{u, t}\right)}{C_{t}-h C_{t-1}}, \\
W_{t} & =\frac{l_{t}^{1 / \eta} \exp \left(z_{u, t}\right)}{\Xi_{t}}, \\
1 & =E_{t} \frac{\beta \Xi_{t+1}}{\Xi_{t}} \frac{r_{t}}{\pi_{t+1}},
\end{aligned}
$$


where $\Xi_{t}$ is the marginal utility of consumption, $C_{t}$ is aggregate consumption, and $\pi_{t}=$ $P_{t} / P_{t-1}$ is the gross inflation rate of final goods' price.

\section{A.2 Firms}

The representative final-good firm produces homogeneous goods $Y_{t}$ by choosing a combination of differentiated intermediate inputs $\left\{Y_{t}(i)\right\}$ so as to maximize profit

$$
P_{t} Y_{t}-\int_{0}^{1} P_{t}(i) Y_{t}(i) d i
$$

subject to the CES production technology

$$
Y_{t}=\left[\int_{0}^{1}\left(Y_{t}(i)\right)^{\frac{\theta-1}{\theta}} d i\right]^{\frac{\theta}{\theta-1}}
$$

where $P_{t}(i)$ is the price of intermediate $\operatorname{good} i$ and $\theta>1$ is the price elasticity of demand for each intermediate good.

The first-order condition for profit maximization yields the final-good firm's demand for intermediate good $i$

$$
Y_{t}(i)=Y_{t}\left(\frac{P_{t}(i)}{P_{t}}\right)^{-\theta} .
$$

Then, the CES production technology leads to

$$
P_{t}=\left[\int_{0}^{1}\left(P_{t}(i)\right)^{1-\theta} d i\right]^{\frac{1}{1-\theta}} .
$$

The final-good market clearing condition is given by

$$
Y_{t}=C_{t}
$$

Each intermediate-good firm $i$ produces one kind of differentiated goods $Y_{t}(i)$ under monopolistic competition. Firm $i$ 's production function is given by

$$
Y_{t}(i)=A_{t} l_{t}(i)
$$

where $A_{t}$ represents the technology level and follows the stochastic process

$$
\log A_{t}=\log a+\log A_{t-1}+z_{a, t}
$$


where $a$ is the steady-state gross rate of technological change, which equals the steady-state gross rate of balanced growth, and $z_{a, t}$ is a (non-stationary) technology shock.

The first-order condition for firm $i$ 's minimization of production cost yields its real marginal cost

$$
m c_{t}(i)=\frac{W_{t}(i)}{A_{t}} .
$$

In the face of the final-good firm's demand (14) and the marginal cost (19), intermediategood firms set prices of their products on a staggered basis as in Calvo (1983). In each period, a fraction $\lambda \in(0,1)$ of firms keeps previous-period prices unchanged, while the remaining fraction $1-\lambda$ of firms sets the price $P_{t}(i)$ so as to maximize the profit function

$$
E_{t} \sum_{j=0}^{\infty} \lambda^{j} Q_{t, t+j}\left(\frac{P_{t}(i)}{P_{t+j}}-m c_{t+j}(i)\right) Y_{t+j}\left(\frac{P_{t}(i)}{P_{t+j}}\right)^{-\theta},
$$

where $Q_{t, t+j}$ is the stochastic discount factor between period $t$ and period $t+j$. For this profit function to be well-defined, it is assumed that the two conditions $\beta \lambda \pi^{\theta-1}<1$ and $\beta \lambda \pi^{\theta+\frac{\theta}{\eta}}<1$, where $\pi$ is the gross rate of trend inflation (i.e., the steady-state value of final goods' price inflation rate), are satisfied.

The first-order condition for profit maximization of intermediate-good firms that reset prices in period $t$ becomes

$$
E_{t} \sum_{j=0}^{\infty}(\beta \lambda)^{j} \frac{\Xi_{t+j}}{\Xi_{t}} Y_{t+j}\left(p_{t}^{*} \prod_{k=1}^{j} \frac{1}{\pi_{t+k}}\right)^{-\theta}\left(p_{t}^{*} \prod_{k=1}^{j} \frac{1}{\pi_{t+k}}-\frac{\theta}{\theta-1} m c_{t+j}^{*}\right)=0,
$$

where the insurance-market equilibrium condition $Q_{t, t+j}=\beta^{j} \Xi_{t+j} / \Xi_{t}$ is used and where $p_{t}^{*}=P_{t}^{*} / P_{t}, P_{t}^{*}$ is the price reset by the firms and $m c_{t+j}^{*}$ is their real marginal cost. From (11), (12), (14), (16), (17), and (19), it follows that the marginal cost is given by

$$
m c_{t+j}^{*}=\left(p_{t}^{*} \prod_{k=1}^{j} \frac{1}{\pi_{t+k}}\right)^{-\frac{\theta}{\eta}}\left(\frac{Y_{t+j}}{A_{t+j}}\right)^{\frac{1}{\eta}}\left(\frac{Y_{t+j}}{A_{t+j}}-h \frac{Y_{t+j-1}}{A_{t+j-1}} \frac{A_{t+j-1}}{A_{t+j}}\right) .
$$

Under the staggered pricing, the final-good price equation (15) can be written as

$$
1=(1-\lambda)\left(p_{t}^{*}\right)^{1-\theta}+\lambda \pi_{t}^{\theta-1} .
$$

\section{A.3 The central bank}

The central bank conducts monetary policy according to a Taylor (1993)-type monetary policy rule. This rule adjusts the policy rate $r_{t}$ in response to the past rates $r_{t-1}, r_{t-2}$, the 
deviations of the gross rates of expected inflation $E_{t} \pi_{t+1}$ and output growth $Y_{t} / Y_{t-1}$ from their trend levels $\pi$ and $a$, and the output gap $x_{t}$ :

$$
\begin{aligned}
\log r_{t}= & \phi_{r 1} \log r_{t-1}+\phi_{r 2} \log r_{t-1}+\left(1-\phi_{r 1}-\phi_{r 2}\right) \\
& \times\left[\log r+\phi_{\pi}\left(\log E_{t} \pi_{t+1}-\log \pi\right)+\phi_{x} \log x_{t}+\phi_{\Delta y}\left(\log \frac{Y_{t}}{Y_{t-1}}-\log a\right)\right]+z_{r, t},
\end{aligned}
$$

where the output gap is defined as

$$
x_{t}=\frac{Y_{t}}{Y_{t}^{n}}
$$

$Y_{t}^{n}$ is the natural rate of output; $z_{r, t}$ is a monetary policy shock; $r$ is the steady-state gross policy rate; and $\phi_{r 1}, \phi_{r 2}, \phi_{\pi}, \phi_{x}, \phi_{\Delta y}$ are the degrees of monetary policy responses to the past policy rates, inflation, the output gap, and output growth. By considering flexible prices (i.e., $\lambda=0$ ) in the intermediate-good price equation (20) and the final-good price equation (22) and combining the resulting two equations with the marginal-cost equation (21), we have the law of motion for the natural rate of output

$$
\left(\frac{Y_{t}^{n}}{A_{t}}\right)^{1+\frac{1}{\eta}}=\frac{\theta-1}{\theta}+h\left(\frac{Y_{t}^{n}}{A_{t}}\right)^{\frac{1}{\eta}} \frac{Y_{t-1}^{n}}{A_{t-1}} \frac{A_{t-1}}{A_{t}} .
$$

The equilibrium conditions are given by (11)-(13), (18), (20)-(24), and (25). Combining these equilibrium conditions, rewriting the resulting equations in terms of the detrended variables $y_{t}=Y_{t} / A_{t}, y_{t}^{n}=Y_{t}^{n} / A_{t}$, and log-linearizing them yields the log-linearized model consisting of (1)-(6). 


\section{References}

[1] Arias, Jonas E., Guido Ascari, Nicola Branzoli, and Efrem Castelnuovo. 2015. "Monetary Policy, Trend Inflation and the Great Moderation: An Alternative Interpretation - Comment." Board of Governors of the Federal Reserve System, International Finance Discussion Papers, No. 1127.

[2] Ascari, Guido, and Tiziano Ropele. 2009. "Trend Inflation, Taylor Principle and Indeterminacy." Journal of Money, Credit and Banking, 41(8): 1557-84.

[3] Ascari, Guido, and Argia M. Sbordone. 2014. "The Macroeconomics of Trend Inflation." Journal of Economic Literature, 52(3): 679-739.

[4] Benati, Luca, and Paolo Surico. 2009. "VAR Analysis and the Great Moderation." American Economic Review, 99(4): 1636-52.

[5] Beyer, Andreas, and Roger E.A. Farmer. 2007. "Testing for Indeterminacy: Comment." American Economic Review, 97(1): 524-29.

[6] Bhattarai, Saroj, Jae Won Lee, and Woong Yong Park. 2012. "Monetary-Fiscal Policy Interactions and Indeterminacy in Postwar US Data." American Economic Review, 102(3): 173-78.

[7] Bhattarai, Saroj, Jae Won Lee, and Woong Yong Park. 2015. "Policy Regimes, Policy Shifts, and U.S. Business Cycles." Review of Economics and Statistics, forthcoming.

[8] Blanchard, Olivier Jean, and Charles M. Kahn. 1980. "The Solution of Linear Difference Models under Rational Expectations." Econometrica, 48(5): 1305-11.

[9] Boivin, Jean, and Marc P. Giannoni. 2006. "Has Monetary Policy Become More Effective?" Review of Economics and Statistics, 88(3): 445-62.

[10] Calvo, Guillermo A. 1983. "Staggered Prices in a Utility-Maximizing Framework." Journal of Monetary Economics, 12(3): 383-98. 
[11] Christiano, Lawrence J., Martin Eichenbaum, and Charles L. Evans. 2005. "Nominal Rigidities and the Dynamic Effects of a Shock to Monetary Policy." Journal of Political Economy, 113(1): 1-45.

[12] Clarida, Richard, Jordi Galí, and Mark Gertler. 2000. "Monetary Policy Rules and Macroeconomic Stability: Evidence and Some Theory." Quarterly Journal of Economics, 115(1): 147-80.

[13] Cogley, Timothy, and Argia M. Sbordone. 2008. "Trend Inflation, Indexation, and Inflation Persistence in the New Keynesian Phillips Curve." American Economic Review, 98(5): 2101-26.

[14] Coibion, Olivier, and Yuriy Gorodnichenko. 2011. "Monetary Policy, Trend Inflation, and the Great Moderation: An Alternative Interpretation." American Economic Review, 101(1): 341-70.

[15] Hirose, Yasuo. 2007. "Sunspot Fluctuations under Zero Nominal Interest Rates." Economics Letters, 97(1): 39-45.

[16] Hirose, Yasuo. 2008. "Equilibrium Indeterminacy and Asset Price Fluctuation in Japan: A Bayesian Investigation." Journal of Money, Credit and Banking, 40(5): 96799.

[17] Hirose, Yasuo. 2013. "Monetary Policy and Sunspot Fluctuations in the United States and the Euro Area." Macroeconomic Dynamics, 17(1): 1-28.

[18] Hornstein, Andreas, and Alexander L. Wolman. 2005. "Trend Inflation, FirmSpecific Capital, and Sticky Prices." Federal Reserve Bank of Richmond Economic Quarterly, Fall.

[19] Justiniano, Alejandro, and Giorgio E. Primiceri. 2008. "The Time-Varying Volatility of Macroeconomic Fluctuations." American Economic Review, 98(3): 60441. 
[20] Kahn, James A., Margaret M. McConnell, and Gabriel Perez-Quiros. 2002. "On the Causes of the Increased Stability of the U.S. Economy." Federal Reserve Bank of New York Economic Policy Review, 8(1): 183-202.

[21] Kehoe, Patrick J., and Virgiliu Midrigan. 2015. "Prices are Sticky After All." Journal of Monetary Economics, 75: 35-53.

[22] Kiley, Michael T. 2007. "Is Moderate-to-High Inflation Inherently Unstable?" International Journal of Central Banking, 3(2): 173-201.

[23] Klenow, Peter J., and Oleksiy Kryvtsov. 2008. "State-Dependent or TimeDependent Pricing: Do It Matter for Recent U.S. Inflation?" Quarterly Journal of Economics, 123(3): 863-904.

[24] Klenow, Peter J., and Benjamin A. Malin. 2010. "Microeconomic Evidence on Price-Setting." In Handbook of Monetary Economics, Vol. 3, eds. Benjamin M. Friedman and Michael Woodford, 231-84. Amsterdam: Elsevier, North-Holland.

[25] Kobayashi, Teruyoshi, and Ichiro Muto. 2013. "A Note on Expectational Stability under Nonzero Trend Inflation." Macroeconomic Dynamics, 17(3): 681-93.

[26] Kurozumi, Takushi. 2014. "Trend Inflation, Sticky Prices, and Expectational Stability." Journal of Economic Dynamics and Control, 42: 175-87.

[27] Kurozumi, Takushi. 2016. "Endogenous Price Stickiness, Trend Inflation, and Macroeconomic Stability." Journal of Money, Credit and Banking, forthcoming.

[28] Kurozumi, Takushi, and Willem Van Zandweghe. 2016a. "Trend Inflation and Equilibrium Stability: Firm-Specific versus Homogeneous Labor." Macroeconomic Dynamics, forthcoming.

[29] Kurozumi, Takushi, and Willem Van Zandweghe. 2016b. "Kinked Demand Curves, the Natural Rate Hypothesis, and Macroeconomic Stability." Review of Economic Dynamics, forthcoming. 
[30] Lubik, Thomas A., and Frank Schorfheide. 2003. "Computing Sunspot Equilibria in Linear Rational Expectations Models." Journal of Economic Dynamics and Control, 28(2): $273-85$.

[31] Lubik, Thomas A., and Frank Schorfheide. 2004. "Testing for Indeterminacy: An Application to U.S. Monetary Policy.” American Economic Review, 94(1): 190-217.

[32] Lubik, Thomas A., and Frank Schorfheide. 2007. "Testing for Indeterminacy: An Application to U.S. Monetary Policy: Reply." American Economic Review, 97(1): $530-33$.

[33] Mavroeidis, Sophocles. 2010. "Monetary Policy Rules and Macroeconomic Stability: Some New Evidence." American Economic Review, 100(1): 491-503.

[34] Nakamura, Emi, and Jon Steinsson. 2008. "Five Facts about Prices: A Reevaluation of Menu Cost Models." Quarterly Journal of Economics, 123(3): 1415-64.

[35] Nakamura, Emi, and Jon Steinsson. 2013. "Price Rigidity: Microeconomic Evidence and Macroeconomic Implications." Annual Review of Economics, 5: 133-63.

[36] Orphanides, Athanasios. 2004. "Monetary Policy Rules, Macroeconomic Stability, and Inflation: A View from the Trenches." Journal of Money, Credit and Banking, $36(2): 151-75$.

[37] Sims, Christopher A. 2002. "Solving Linear Rational Expectations Models." Computational Economics, 20(1-2): 1-20.

[38] Sims, Christopher A., and Tao Zha. 2006. "Were There Regime Switches in U.S. Monetary Policy?" American Economic Review, 96(1): 54-81.

[39] Smets, Frank, and Rafael Wouters. 2007. "Shocks and Frictions in US Business Cycles: A Bayesian DSGE Approach.” American Economic Review, 97(3): 586-606.

[40] Taylor, John B. 1993. "Discretion Versus Policy Rules in Practice." CarnegieRochester Conference Series on Public Policy, 39(1): 195-214. 
Table 1: Prior distributions of parameters

\begin{tabular}{llcc}
\hline \hline Parameter & Distribution & Mean & Standard deviation \\
\hline$h$ & Beta & 0.500 & 0.200 \\
$\theta$ & Gamma & 10.000 & 2.500 \\
$\lambda$ & Beta & 0.500 & 0.100 \\
$\phi_{\pi}$ & Gamma & 1.500 & 0.500 \\
$\phi_{x}$ & Gamma & 0.125 & 0.100 \\
$\phi_{\Delta y}$ & Gamma & 0.750 & 0.100 \\
$\phi_{r 1}$ & Normal & 1.000 & 0.200 \\
$\phi_{r 2}$ & Normal & 0.000 & 0.200 \\
$\bar{a}$ & Normal & 0.295 & 0.100 \\
$\bar{\pi}$ & Normal & 0.953 & 0.500 \\
$\bar{r}$ & Gamma & 1.623 & 0.250 \\
$\rho_{u}$ & Beta & 0.700 & 0.200 \\
$\rho_{a}$ & Beta & 0.700 & 0.200 \\
$\rho_{r}$ & Beta & 0.700 & 0.200 \\
$\sigma_{u}$ & Inverse gamma & 0.500 & $\infty$ \\
$\sigma_{a}$ & Inverse gamma & 0.500 & $\infty$ \\
$\sigma_{r}$ & Inverse gamma & 0.500 & $\infty$ \\
$\sigma_{\zeta}$ & Inverse gamma & 0.500 & $\infty$ \\
$M_{u}$ & Normal & 0.000 & 1.000 \\
$M_{a}$ & Normal & 0.000 & 1.000 \\
$M_{r}$ & Normal & 0.000 & 1.000 \\
\hline & & & \\
\hline
\end{tabular}

Notes: The inverse gamma priors are of the form $p(\sigma \mid \nu, s) \propto \sigma^{-\nu-1} e^{-\nu s^{2} / 2 \sigma^{2}}$, where $\nu=2$ and $s=0.282$. The prior probability of determinacy of equilibrium is 0.493 . 
Table 2: Posterior distributions of parameters

\begin{tabular}{|c|c|c|c|c|c|}
\hline \multirow[b]{2}{*}{ Parameter } & \multirow[b]{2}{*}{ Prior mean } & \multicolumn{2}{|c|}{ Pre-1979 period } & \multicolumn{2}{|c|}{ Post-1982 period } \\
\hline & & Mean & $90 \%$ interval & Mean & $90 \%$ interval \\
\hline$h$ & 0.500 & 0.561 & {$[0.412,0.727]$} & 0.469 & {$[0.345,0.588]$} \\
\hline$\theta$ & 10.000 & 10.610 & {$[6.960,14.104]$} & 8.921 & {$[5.207,12.405]$} \\
\hline$\lambda$ & 0.500 & 0.577 & {$[0.465,0.693]$} & 0.385 & {$[0.279,0.494]$} \\
\hline$\phi_{\pi}$ & 1.500 & 1.310 & {$[0.876,1.726]$} & 2.705 & {$[2.080,3.279]$} \\
\hline$\phi_{x}$ & 0.125 & 0.428 & {$[0.279,0.612]$} & 0.111 & {$[0.002,0.226]$} \\
\hline$\phi_{\Delta y}$ & 0.750 & 0.731 & {$[0.569,0.879]$} & 0.767 & {$[0.615,0.922]$} \\
\hline$\phi_{r 1}$ & 1.000 & 0.844 & {$[0.683,1.014]$} & 1.038 & {$[0.885,1.195]$} \\
\hline$\phi_{r 2}$ & 0.000 & -0.094 & {$[-0.243,0.075]$} & -0.312 & {$[-0.454,-0.176]$} \\
\hline $\bar{a}$ & 0.295 & 0.277 & {$[0.140,0.424]$} & 0.349 & {$[0.230,0.476]$} \\
\hline $\bar{\pi}$ & 0.953 & 1.188 & {$[0.855,1.496]$} & 0.737 & {$[0.595,0.889]$} \\
\hline $\bar{r}$ & 1.623 & 1.595 & {$[1.356,1.847]$} & 1.554 & {$[1.265,1.848]$} \\
\hline$\rho_{u}$ & 0.700 & 0.679 & {$[0.514,0.847]$} & 0.931 & {$[0.897,0.970]$} \\
\hline$\rho_{a}$ & 0.700 & 0.629 & {$[0.370,0.864]$} & 0.301 & {$[0.106,0.482]$} \\
\hline$\rho_{r}$ & 0.700 & 0.304 & {$[0.111,0.487]$} & 0.257 & {$[0.110,0.402]$} \\
\hline$\sigma_{u}$ & 0.500 & 2.874 & {$[1.559,4.233]$} & 2.203 & {$[1.202,3.300]$} \\
\hline$\sigma_{a}$ & 0.500 & 0.523 & {$[0.185,0.857]$} & 0.794 & {$[0.609,0.986]$} \\
\hline$\sigma_{r}$ & 0.500 & 0.229 & {$[0.177,0.276]$} & 0.155 & {$[0.119,0.190]$} \\
\hline$\sigma_{\zeta}$ & 0.500 & 0.206 & {$[0.117,0.292]$} & - & - \\
\hline$M_{u}$ & 0.000 & -0.019 & {$[-0.078,0.037]$} & - & - \\
\hline$M_{a}$ & 0.000 & -0.725 & {$[-1.331,-0.217]$} & - & - \\
\hline$M_{r}$ & 0.000 & -0.462 & {$[-1.005,0.015]$} & - & - \\
\hline
\end{tabular}

Note: The posterior means and $90 \%$ credible intervals are calculated from the draws generated using the Metropolis-Hastings algorithm. For the post-1982 sample, $\sigma_{\zeta}, M_{u}, M_{a}$, and $M_{r}$ are not identified because all the posterior draws lie in the determinacy region of the parameter space. 
(a) Pre-1979 estimates of all model parameters

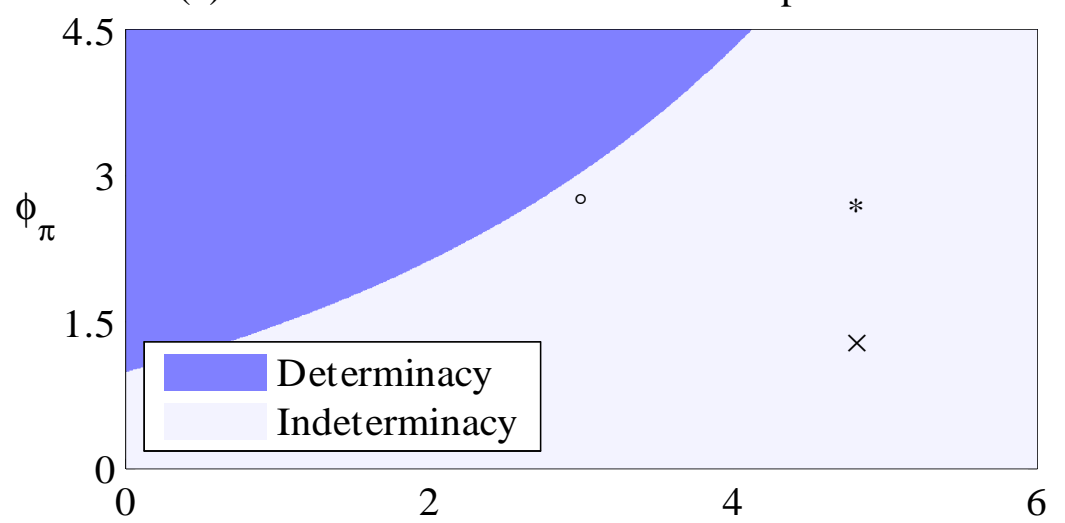

(b) Post-1982 estimates of all monetary policy responses

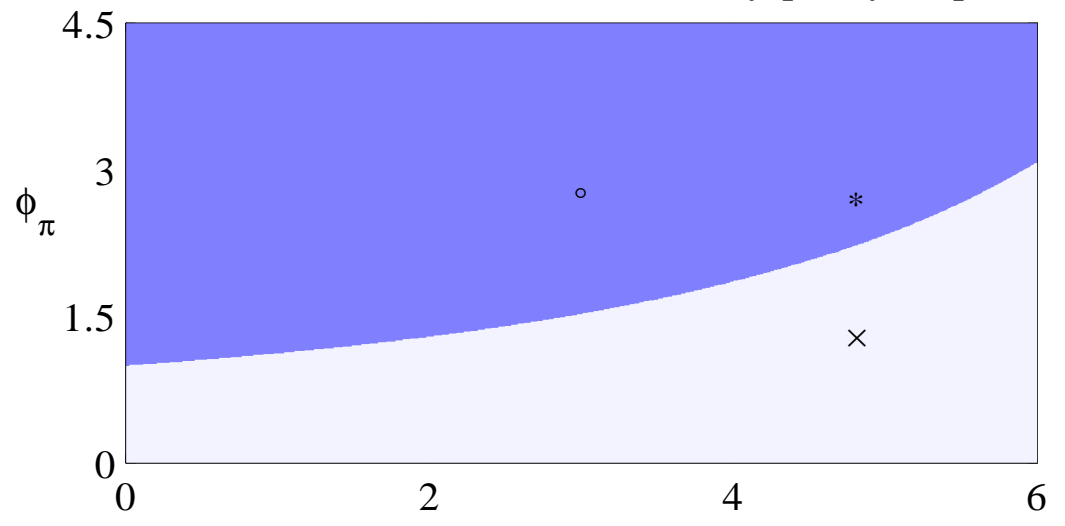

(c) Post-1982 estimates of all model parameters

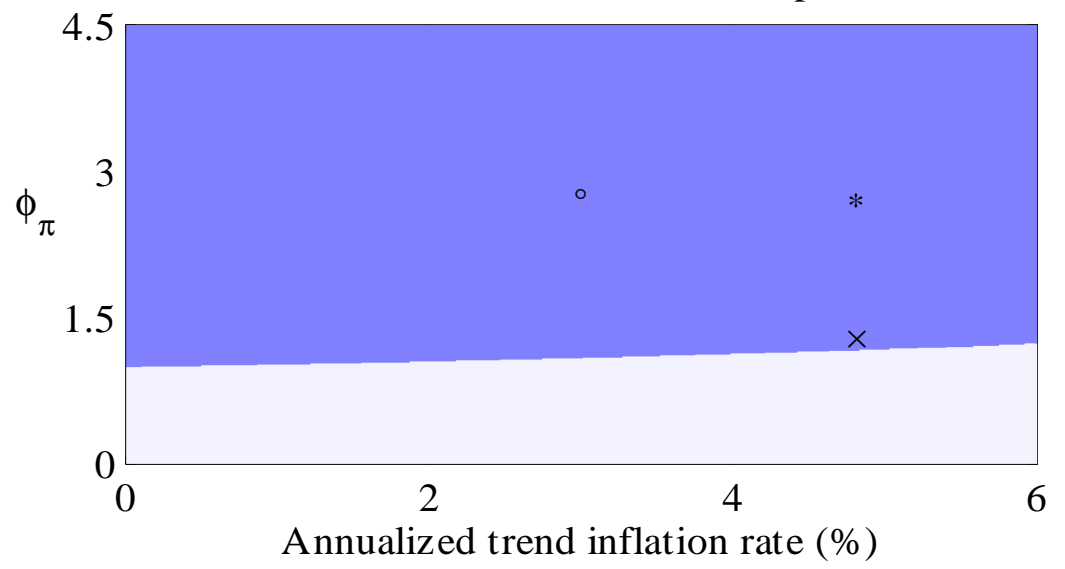

Figure 1: Equilibrium determinacy region of the parameter space

Notes: The figure shows the equilibrium determinacy region of the parameter space of the annualized trend inflation rate $4 \bar{\pi}$ and the monetary policy response to inflation $\phi_{\pi}$. In each panel, the mark "×", "*", and "०" respectively represent the pair of $\left(4 \bar{\pi}^{\text {pre } 79}, \phi_{\pi}^{\text {pre } 79}\right),\left(4 \bar{\pi}^{\text {pre } 79}, \phi_{\pi}^{\text {post } 82}\right)$, and $\left(4 \bar{\pi}^{\text {post } 82}, \phi_{\pi}^{\text {post } 82}\right)$, where $\bar{\pi}^{\text {pre } 79}$, $\phi_{\pi}^{\text {pre } 79}, \bar{\pi}^{\text {post } 82}$, and $\phi_{\pi}^{\text {post82 }}$ denote the posterior-mean estimates of the trend inflation rate and the policy response to inflation for the pre-1979 and post-1982 periods. 